\title{
Incidence of Urinary Tract Infections, among Adolescent and Adult Women in Ogbete Coal Camp, Enugu
}

\author{
Onwujekwe Emmanuel Chijioke ${ }^{1, *}$, Agbo Angela ${ }^{2}$, Ezemba Constance Chinyere ${ }^{1}$ \\ ${ }^{1}$ Department of Microbiology, Coal City University, Enugu, Nigeria \\ ${ }^{2}$ Department of Microbiology Laboratory, Coal camp Health Centre, Enugu, Nigeria
}

Copyright $@ 2018$ by authors, all rights reserved. Authors agree that this article remains permanently open access under the terms of the Creative Commons Attribution License 4.0 International License

\begin{abstract}
This study was to determine the bacteria that are prevalent in Urinary tract infections and the sensitivity of organisms isolated from the urine of adolescent and adult women of 8- 52 years old in Ogbete Coal camp in Enugu metropolis, south east Nigeria. A total of 218 individuals, both in and out patients were investigated, 197 (90.3\%) women were diagnosed for Urinary tract infections. Therefore, incidence of UTI were prevalent in the age groups of $13-17$ and $18-22$, with $P$ value $(p=0.047$ and S.D of \pm 5.6$)$. The microorganisms implicated in infection were bacteria, fungi, yeast and protozoa. Among the bacteria, two were identified as Gram positive cocci i.e. Staphylococcus aureus and Staphylococcus saprophyticus, while Gram negative bacilli were Escherichia coli, Klebsiella, Proteus, Pseudomonas aeruginosa. Yeast like fungus Candida albican, protozoan (Trichomonas vaginalis) was also identified. The isolated organism which was prevalent was Staphylococcus aureus (48.2\%); followed by Escherichia coli (34.5\%). Also, Pseudomonas aeruginosa, Proteus and Klebsiella were isolated. Factors responsible for frequent cases of Urinary tract infections among diagnosed women include shortness of urethra among the females, lack of personal hygiene, sexual intercourse, socio economic challenges in various homes and others. Sensitivity profiles revealed that Augumentin was highly susceptible to Staphylococcus aureus (65\%) while Escherichia coli were highly resistant to commonly used drugs such as Ampicillin, and Cloxacillin while Gentamycin was the most active against bacteria isolates.
\end{abstract}

Keywords Urinary Tract Infection, Adolescent Women, Antimicrobial Sensitivity, Staphylococcus aureus, Escherichia coli

\section{Introduction}

Urinary tract infection (UTI) is an infection in any part of the urinary system - kidneys, ureters, bladder and urethra [1]. Worldwide, about 152 million people are diagnosed with urinary tract infections each year with morbidity of about 196,500 (WHO; 2017 [2]). In developing countries like Nigeria, the rate of UTI's is high especially among women [3]. Bacteriuria is defined as the presence of $>10^{5}$ colonies of a single pathogen per milliliter of urine. Urinary tract infection is more common in females than males as a result of opening of the urethra near the anus and shortness of urethra in females [4]. According to Akobi et al [5], urine of females has more suitable $\mathrm{pH}$ and osmotic pressure for the growth of Escherichia coli than urine from males. Urinary tract infection is classified into six categories as uncomplicated infection, complicated infection, isolated infection, unresolved infection, re-infection, and relapse infection [6]. Notable clinical symptoms of urinary tract infections include lower abdominal pain, urgency and frequency of micturition, dysuria, itching, pyuria, formation of blisters and ulcers in genital areas. Bacteria are the main causes of urinary tract infections among individual worldwide [7]. Urinary tract infections are commonly caused by bacteria such as Escherichia coli, Klebsiella sp, Proteus, Enterococcus faecalis, and Enterobacter, Pseudomonas aeruginosa, Staphylococcus aureus. Group B Streptococcus is usually reported with increased rates in patients with urological disorders and following repetitive course of antibiotic treatment. The prevalence and the degree of occurrence of one or two of these organisms are dependent on the environment (Omonigho et al, [1]). High sexual activities, poor hygiene, low economic status, are some risk factors that predispose adolescent and adult women with urinary tract infections [9]. According to Azubike et al, [10], commonest mode of infection is the ascending route, through which organisms of the bowel flora contaminated the urethra, ascend to the bladder and migrate to the kidney or prostrate. Knowledge about the type of pathogens responsible for Urinary tract infections and their susceptibility patterns may help clinicians to choose the right empirical treatment [11]. Therefore, this study aims to determine the bacteria that are prevalent in urinary tract 
infections in adolescent women and adult women, and also the antimicrobial susceptibility profiles of drugs used in the treatment of such infections.

\section{Materials and Methods}

\section{Study Area}

Ogbete Coal camp area of Enugu is located in Enugu North local government in the heart of Enugu. The area is densely populated as a result of its proximity to Ogbete main market, which is the largest market in Enugu state. Also the presence of an automobile market at the Ogbete Coal camp town contributed to the dense population of this area. Therefore, the people of this area are mainly traders, artisans and students. There is government owned institutions as well as hotels around the area.

\section{Study Population}

The research was a retrospective studies carried out between May 2016 and May 2017 and was conducted in the microbiology section at Ogbete Coal camp Health Centre for urinary tract infections issues. This got the approval of the ethical committee of the Health Centre. Verbal informed consent was obtained from all patients prior to specimen collection and the permission to that effect was obtained from the ethical committee of the health center. Their urine sample was obtained through a mid-stream catch technique.

\section{Sample Collection}

Two hundred and eighteen (218) mid-stream urine (MSU) samples were collected inside sterile bijou bottles from the patients. They were instructed on how to collect the samples. The samples were labelled and processed within 30 minutes to 1 hour of sample collection.

Ten $\mathrm{ml}$ of each well mixed urine sample was centrifuged at $2000 \mathrm{~g}$ for 5 minutes. The supernatant was discarded and a drop of the deposit was examined microscopically at high magnification for pus cells, red blood cells, epithelial cells, cast, crystal, yeast-like cells and Trichomonas vaginalis. Pus cells $>5$ per high power field were significant in an individual.

\section{List of Materials and Reagents}

Materials used in the study includes spatula, bijou bottles, stopper, masking tape, conical flask, autoclave, gas cylinder, Bunsen burner, incubator, refrigerator, electronic weighing balance, colony counter, marker, Petri dish, wire loops, slides, test tube glass, pipette, centrifuge , microscope. Nutrient agar, MacConkey agar, blood agar, distilled water, crystal violet, lugol iodine, acetone, caramel, and antimicrobial sensitivity disc.

\section{Sample Processing}

Urine sample were cultured on MacConkey agar and Blood agar. The agar was prepared and sterilized based on the manufacturer's instruction using the autoclave. After sterilizing, the media was allowed to solidify and at temperature of $50^{\circ} \mathrm{C}-55^{\circ} \mathrm{C}$, it was dispensed into sterile Petri dish. The inoculation was carried out and the media incubated for about 24 hours at $37^{\circ} \mathrm{C}$. The organism grown was sub-cultured so as to isolate pure cultures of organisms. A count of $>10^{5}$ CFU (Colony forming unit) was considered significant to indicate UTI. Isolated bacterial species were characterized by Gram stain followed by microscopic examination, motility and biochemical tests and bacteria identification was based on standard culture and biochemical characteristics of the isolates as described by Omer and Fadil [12] and Cheesbrough [4].

\section{Antimicrobial Sensitivity Testing}

The susceptibility testing was carried out using disc diffusion technique as recommended by National Committee for Clinical Laboratory Standards (NCCLS) [13]. The bacterial isolates and standards strains of Escherichia coli ATCC 25922, Enterococcus faecalis 29212, Pseudomonas aeruginosa ATCC 27853 were used for quality control. The antimicrobials used are: Ceftriaxone, Ampicillin, Cloxacilllin, Augumentin, Streptomycin, Azythromycin, Gentamycin, Cefuroxime, Cotrimoxazole, Nitrofurantoin, Nalidixic Acid.

Statistical Analysis: This data was analysed using SPSS version 20.0.

\section{Results}

A total of 197 (90.3\%) out 218 samples collected were confirmed positive with urinary infections. The age distribution of urinary tract infections in women are shown in table 1 . Out of the nine age groups represented in the table, positive bacterial isolates was prevalent in individuals between $18-22$, and 13-17 years. Bacterial isolates was least in individual between the age group 47-52. The bacterial species implicated in the urinary tract infections are Escherichia coli, Klebsiella sp, Staphylococcus saprophyticus, Staphylococcus aureus, Proteus mirabilis and Pseudomonas aeruginosa. The frequency of occurrence of isolates is presented in table 2 . Staphylococcus aureus was found to be the most prevalent organism among the isolates, with $48.2 \%$ occurrence. This was followed by Escherichia coli which accounted for $34.5 \%$ of the isolates. Staphylococcus saprophyticus was least frequently isolated.

Table 3; showed varying antimicrobial susceptibility 
pattern of isolates to the various antimicrobials used. Gentamycin was highly effective against most bacterial isolates. Ampicillin was virtually useless against all bacterial isolate. Table 5 , showed the characteristics of bacteria isolates. Table 6, showed the microscopy findings of urine deposits.

\section{Discussion}

Mid-stream catch technique was used to ensure those normal floras were flushed before the sample for analysis was obtained [4]. Frequent voiding is necessary to flush out invading bacteria from the walls of urethra $[4,14]$.

The result of this study showed that among the population of 218 samples, 197 (90.3\%) were diagnosed positive of bacterial infections. Therefore, incidence of UTI were prevalent in the age groups of 13-17 and 18-22, with $P$ value $(p=0.047$ and S.D of \pm 5.6$)$ statistically not significant. The frequency of occurrence of isolates is presented in (Table 2). Staphylococcus aureus is a predominant pathogen which accounted for $48.2 \%$ of the bacteria isolates that caused urinary tract infection in adolescent women; this may be attributed to high sexual activities among their age group [9]. Escherichia coli also had a significant number which accounted for $34.5 \%$ of the isolates that caused urinary tract infection in women. This is in line with the work of Doud et.al [15]. The reason for the high prevalence of Escherichia coli can also be attributed to the suitable $\mathrm{pH}$ and osmotic pressure provided by the female urine [5]. Klebsiella $s p$ was responsible for $6.6 \%$ of the isolates. Proteus specie accounted for $4.0 \%$; a Gram- negative bacterium and flora of the intestinal tract that causes infection when it makes its way from the intestine to urinary bladder and urethra. Staphylococcus saprophyticus was the least among the bacteria isolates with $1.5 \%$ occurrence. However, this result agrees with the findings of MMDT, that about $40 \%$ of the urinary tract infections are caused by Gram negative species [16].

This study (Table 1) reports high incidence of UTI's between age groups 18 and 22years (98.1\%), and 13-17 years $(96.1 \%)$. The most common uropathogen isolated in this study was Staphylococcus aureus. This findings is similar to two reports in Benin City (urban settlement) [17], [18], and findings of Akinola et al [19].These reports were on asymptomatic bacteriuria against the present study that deals on symptomatic bacteriuria. However, our findings are contrary to the findings of Bankole et al [9], and Akobi et al [5], who reported Escherichia coli as the predominant isolates.

The high incidence of urinary tract infection in women as earlier mentioned is as a result of shortness of urethra, high sexual activity and closeness of urethral opening to the anus [9]. Also, socio-economic factors, is also a major risk factor as mentioned earlier [10]. Some homes where some of the studied population lives, were highly polluted environment, with unsuitable toilet facilities thereby exposing such inhabitants to numerous pathogenic microorganisms.
Antibiotic abuse and practicing incomplete antibiotic dosage has highly promoted the dissemination of multi drug resistant bacteria [20]. Staphylococcus aureus was the highest uropathogen showed high susceptibility to Nitrofurantoin and least susceptible to Cloxacillin. Staphylococcus saprophyticus followed similar pattern of susceptibility with Staphylococcus aureus. The present study found the Escherichia coli and klebsiella species isolates to be highly resistant to the commonly used drugs such of the Penicillin group such as Ampicillin and Cloxacillin. Ahmed et al [6] reported that Amoxicillin, Ampicillin, and Sulfanomides are no longer the drug of choice for empirical treatment because of widespread emergence of resistance in $15-20 \%$ of E.coli in several areas of USA and other countries. However, the antimicrobial susceptibility profile indicates that Nitrofurantoin (69.1\%) were the most active agents against Escherichia coli. Aminoglycosides, example (Gentamycin and Augumentin) are the next drugs that are most susceptible to the isolates by (58.8\%) and (51.4\%) respectively. This result is in agreement to the recommendations of Akobi et al, [5]. Klebsiella pneumonia was susceptible to Nitrofurantoin and Cefuroxime both by (76.6\%), but was completely resistant to Ampicillin. Proteus was highly susceptible to Gentamycin and Ceftriaxone but was also highly resistant to Streptomycin, Ampicillin, and Nitrofurantoin. Pseudomonas aeruginosa was moderately susceptible to Gentamycin and Ceftriaxone. Proteus sp and P.aeruginosa isolates were resistant to most antimicrobials. Most bacterial isolates was least susceptible to Cotrimoxazole. This study is similar to the findings by Mezue et al, [21] at University of Nigeria found Cotrimoxazole to be virtually useless against uropathogen. The resistant of most of the isolates to the penicillin group could be as a result of long term use of these drugs over the years.

However, patients should be advised and encouraged to drink plenty of fluids (two to three liters per day) and to urinate frequently to help flush bacteria from the bladder. Avoiding multiple sexual partners will reduce the risk of both UTI's and sexually transmitted infections. Women are encouraged to avoid spermicidial contraceptive, diaphragms and vaginal douching, which may irritate the vagina and urethra; facilitate the entry and colonization of bacteria within the urinary tract. Meanwhile, some recent studies by Ahmed et al [6], [22], [23], [24], [25] have suggested alternative therapies other than antimicrobials in the treatment of RUTI'S. Some of the measures include the use of Cranberry juice and tablets, acupuncture, probiotics such as Lactobacillus found in fermented milk products; mainly yoghurt, as well as immunoprophylaxis. Nevertheless, more clinical studies need to be carried out to determine their role in RUTI prevention.

\section{Conclusions}

Staphylococcus aureus is a predominant organism 
causing urinary tract infections in adolescent and adult women as a result of unprotected sex and high sexual activity at their age. Escherichia coli are also frequently isolated organism that causes UTI's. Urinary tract infections occur mostly in females than their male counterparts. It has dangerous effect when left untreated. The prevalent isolates were susceptible to Augumentin,
Nitrofurantoin and Gentamycin. This study advocates early diagnosis of urinary tract infection, regular monitoring of drug resistant phenotype of UTI pathogens to improve public health treatment and reduce cases of infections with other complications caused as a result of urinary pathogens in our society.

\section{Table of Results}

Table 1; showed prevalence of infections was most among women between the ages of 18-22 and 13 and 17 (98.1\% and 96.1\%)) positive cases. Age group 47-52, had the least incidence rate with 5 (50\%) positive cases.

Table 1. Incidence of UTI's in relation to Age among adolescent and adult women

\begin{tabular}{|c|c|c|c|}
\hline Age interval & No Tested & \% positive & \% negative \\
\hline $8-12$ & 19 & $11(57.9)$ & $8(42.1)$ \\
\hline $13-17$ & 51 & $49(96.1)$ & $2(3.9)$ \\
\hline $18-22$ & 53 & $82(98.1)$ & $7(63.6)$ \\
\hline $23-27$ & 11 & $35(94.6)$ & $2(5.4)$ \\
\hline $28-32$ & 37 & $10(71.4)$ & $4(28.6)$ \\
\hline $33-36$ & 14 & $6(75)$ & $2(25)$ \\
\hline $37-41$ & 14 & $11(78.6)$ & $3(21.4)$ \\
\hline $42-46$ & 10 & $5(50)$ & $5(50)$ \\
\hline $47-51$ & & & \\
\hline
\end{tabular}

Table 2. Prevalence of organisms isolated from the urine

\begin{tabular}{|c|c|c|}
\hline Organism & Number of patients & Number of occurrence (\%) \\
\hline Escherichia coli & 197 & $68(34.5 \%)$ \\
\hline Klebsiella & 197 & $13(6.6 \%)$ \\
\hline Staphylococcus saprophyticus & 197 & $3(1.5 \%)$ \\
\hline Staphylococcus aureus & 197 & $95(48.2 \%)$ \\
\hline Proteus & 197 & $8(4.0 \%)$ \\
\hline P. aeruginosa & 197 & $11(5.6 \%)$ \\
\hline
\end{tabular}

Staphylococcus aureus was most prevalent in the urine samples (48\%), next was Escherichia coli 34\% and the least prevalent was Staphylococcus saprophyticus.

Table 3; showed varying antimicrobial susceptibility pattern of isolates to the antimicrobials used.

Table 3. Susceptibility Profiles of Urinary Bacterial Isolates

\begin{tabular}{|c|c|c|c|c|c|c|}
\hline ANTIBIOTICS & $\begin{array}{l}\text { E. coli } \\
(\mathrm{N}=68)\end{array}$ & $\begin{array}{l}\text { K. pneumonia } \\
(\mathrm{N}=13)\end{array}$ & $\begin{array}{l}\text { S. saprophyticus } \\
(\mathrm{N}=3)\end{array}$ & $\begin{array}{l}\text { S. aureus } \\
(\mathrm{N}=95)\end{array}$ & $\begin{array}{l}\text { P. mirabilis } \\
(\mathrm{N}=8)\end{array}$ & $\begin{array}{l}\text { P. aeruginosa } \\
(\mathrm{N}=11)\end{array}$ \\
\hline CEFT & $26(38.2 \%)$ & $4(30.7 \%)$ & $1(33.3 \%)$ & 19 (20\%) & $6(75 \%)$ & $0(0.0 \%)$ \\
\hline AMP & 2 (2.9\%) & $0(0.0 \%)$ & $0(0.0 \%)$ & $4(4.2 \%)$ & $0(0.0 \%)$ & NA \\
\hline CLOX & NA & NA & $1(33.3 \%)$ & $14(14.7)$ & NA & NA \\
\hline AUG & 35 (51.4\%) & $4(30.7 \%)$ & 2 (66.6\%) & 62 (65.2\%) & $0(0.0 \%)$ & $0(0.0 \%)$ \\
\hline STREPT & $20(29.4 \%)$ & $6(46.1 \%)$ & $1(33.3 \%)$ & $20(21.0 \%)$ & $0(0.0 \%)$ & $4(36.3 \%)$ \\
\hline AZY & $29(42.6 \%)$ & $4(30.7 \%)$ & 1 (33.3\%) & 32 (33.6\%) & $6(75 \%)$ & $0(0.0 \%)$ \\
\hline GENT & $40(58.8 \%)$ & $4(30.7 \%)$ & $1(33.3 \%)$ & $29(30.5 \%)$ & $6(75 \%)$ & $4(36.3 \%)$ \\
\hline $\mathrm{CEF}$ & $7(10.2 \%)$ & 10 (76.9\%) & $0(0.0 \%)$ & 18 (18.9\%) & $0(0.0 \%)$ & $0(0.0 \%)$ \\
\hline $\mathrm{COT}$ & $9(13 \%)$ & $2(15.3 \%)$ & $1(33.3 \%)$ & 19 (20\%) & $4(50 \%)$ & $0(0.0 \%)$ \\
\hline NIT & 47 (69.1\%) & $10(76.9 \%)$ & $2(66.6 \%)$ & 47 (49.4\%) & $0(0.0 \%)$ & NA \\
\hline NAL & 27 (39.7\%) & $4(30.7 \%)$ & $0(0.0 \%)$ & $16(16.8 \%)$ & $0(0.0 \%)$ & NA \\
\hline
\end{tabular}

Bacteria Isolates with Zone of inhibition $=16 \mathrm{~mm}$ is sensitive while $<15 \mathrm{~mm}$ is resistant to a particular antibiotics. CEFT= CEFTRIAXONE. $\mathrm{AMP}=$ AMPICILLIN. CLOX= CLOXACILLIN. AUG= AUGUMENTIN. STREPT=STREPTOMYCIN. AZY= AZYTHROMYCIN. GENT $=$ GENTAMYCIN. CEF=CEFUROXIME. COT=COTRIMOXAZOLE. NIT= NITROFURANTOIN. NAL=NALIDIXIC ACID. N= TOTAL NUMBER. 
A total of 42 samples were resistant to either one or two antimicrobials used in bacteria susceptibility testing. Staphylococcus aureus, the most frequently isolated bacteriuria showed high susceptibility to Augumentin (65.2\%) and Nitrofurantoin (49.4\%) and least susceptible to Ampicillin (4.2\%). Escherichia coli, second frequently isolated bacteriuria was susceptible to Nitrofurantoin (69.1\%) and Gentamycin (58.8\%) but least susceptible to Ampicillin (2.9\%). Klebsiella sp was susceptible to Ceftriaxone and Nitrofurantoin both by (76.9\%), however was completely resistant to ampicillin by (100\%).
Staphylococcus saprophyticus was susceptible to Augumentin and Nitrofurantoin both by (66.6\%) and completely resistant to Ampicillin and Nalidixic acid both by (100\%). Proteus mirabilis was susceptible Ceftriaxone, Azythromycin, and Gentamycin by (75.5\%) but showed (100\%) resistance to Ceftriaxone, Augumentin, Streptomycin, Cefuroxime, Nitrofurantoin and Nalidixic acid. Pseudomonas aeruginosa was moderately susceptible to Streptomycin and Gentamycin both by (36.6\%) and resistant to other antimicrobials.

Table 4. Pattern of bacterial occurrence in age groups

\begin{tabular}{|c|c|c|c|c|c|c|}
\hline Age group & E. coli & klebsiella & S. aureus & proteus & p. aeruginosa & S. saprophyticus \\
\hline $8-12$ & 3 & 1 & 8 & - & - & - \\
\hline $13-17$ & 14 & 1 & 33 & - & - & 1 \\
\hline $18-22$ & 20 & 5 & 22 & 2 & - & - \\
\hline $23-27$ & 3 & 1 & 4 & - & 6 & - \\
\hline $28-32$ & 16 & 2 & 11 & 2 & 1 & - \\
\hline $33-37$ & 7 & - & 2 & - & 1 & - \\
\hline $38-42$ & 1 & 2 & 3 & 4 & 2 & - \\
\hline $43-47$ & 4 & 1 & 6 & - & - & - \\
\hline $48-52$ & 2 & - & 4 & 8 & & - \\
\hline
\end{tabular}

Staphylococcus aureus was found to be main urinary pathogen among children between 8-11 years. It was observed that Escherichia coli and Staphylococcus aureus were implicated in infections in adolescent between 18-22 years as well as in women between 42-46, and 47-51

Table 5. Identification of characteristics of bacterial isolates

\begin{tabular}{|c|c|c|c|c|c|c|c|c|}
\hline Catalase & Coagulase & Oxidase & Urease & Indole & Glucose & Sucrose & Lactose & Organism \\
\hline+ & - & - & - & + & A & A & AG & Escherichia coli \\
\hline+ & ND & - & + & - & AG & A & AG & Klebsiella sp. \\
\hline+ & + & - & - & ND & A & A & A & S. aureus \\
\hline- & ND & - & + & + & - & A & ND & Proteus \\
\hline ND & ND & + & - & ND & ND & ND & ND & P. aeruginosa \\
\hline+ & - & - & - & ND & A & A & A & S. saprophyticus \\
\hline
\end{tabular}

Key: +=Positive, -=Negative, A=Acid, G=Gas, ND= Not Done.

Table 6. Microscopy of urine deposits

\begin{tabular}{|c|c|c|c|c|c|c|}
\hline Age & Appearance & WBC & RBC & Yeast & Epithelia cells & T. vaginalis \\
\hline $8-12$ & Amber, \& cloudy & $11-20$ & F & F & F, M & F \\
\hline $13-17$ & Amber, red \& cloudy, & $11-40$ & MD & F & M & F \\
\hline $18-22$ & Amber, red \& cloudy & $11-40,40-$ & F, M & M & F & MD \\
\hline $23-27$ & Amber, red & $11-40$ & F, MD, M & M & M & MD \\
\hline $28-32$ & Amber, red \& cloudy & $11-40,40-$ & MD, M & M & MD & F \\
\hline $33-37$ & Red \& cloudy & $11-40,40-$ & F, M, MD & M & F & M \\
\hline $38-42$ & Red \& cloudy & $11-40,40-$ & MD & M & M & MD, M \\
\hline $43-47$ & Amber red \& cloudy & $11-40,40-$ & M & M & M & MD \\
\hline $48-52$ & Amber, red \& cloudy & $11-40$ & M & M & F & MD \\
\hline
\end{tabular}

Key: $\mathrm{F}=$ Few, $\mathrm{MD}=$ Moderate, $\mathrm{M}=$ Many 
In urine microscopy, white blood cells (pus cells) were found. Up to 10WBCs / HPF (high power field, i.e. using $40 \mathrm{x}$ objectives) was considered as few in number. Moderate number: 11-40/ HPF, and more than $40 \mathrm{WBC} /$ HPF, was considered as many.

\section{Acknowledgements}

We are very grateful to the entire staff of Faculty of Natural and Applied Science Coal City University Enugu, and Ogbete Coal camp Health Centre Enugu for their cooperation and for given us access to their research laboratories.

\section{REFERENCES}

[1] S.E. Omonigho, E.E. Obasi, R.N. Akukalia. In Vitro Resistance of Urinary Isolates of Escherichia coli and Klebsiella species to Nalidixic Acid, 2001

[2] World health organization (WHO). Accessed on $24^{\text {th }}$ June, 2017.

[3] F. A. Orret, G.K. Davis. A comparison of the antimicrobial susceptibility profile of urinary pathogens for the years 1999 and 2003. West Indian Medical Journal, Vol. 55, No 95, 95-99, 2006.

[4] M. Cheesbrough. District Laboratory Practice in Tropical Countries part 11, Cambridge University press, UK, 2004.

[5] O.A. Akobi, H.E. Inyinbor, E.G. Emumwem, S O. Ogedengbe, E.O Uzoigwe, R.O. Abayomi, E.F. Emumwem, M.Y. Okorie Ebie, Y. T. Kandakai-Olukemi,J. Ayanbadejo, K.B. Tanyiga. Urinary tract infections in a Nigeria military Hospital Niger. Journal of Microbiology. Vol 15, No1, 31-37, 2001

[6] A. Ahmed, A. Ghadeer. Recurrent Urinary Tract Infection Management in Women, Sultan Qaboos University Medical Journal, 2013.

[7] M.Y. Ebie, Y. T. Kandakai-Olukemi J. Ayanbadejo, K.B. Tanyiga. Urinary tract infections in a Nigeria military Hospital, Nigerian Journal of Microbiology Vol15, No 1, 31-37, 2001

[8] M.N. Guentzel. Escherichia klebsiella, Enterobacter, Serratia, Citrobacter, and Proteus. Barron's Medical Microbiology $4^{\text {th }}$ ed. Univ of Texas Medical Branch, 1996.

[9] B H. Oladeinde, R. Omoregie, M. Olley, J.A. Anunibe. Urinary tract infection in a rural community in Nigeria. North American Journal of Medical Sciences. Vol. 3 no 2, 75-77, 2011.

[10] J.C. Azubike, K.E.O Nkeaniginieme. Paediatrics and Appllied Health in Nigeria, 1999.
[11] C.M. Ogbukagu, V.N. Anakwenze, C.C. Ekwealor, C.C. Ezemba, I.A. Ekwealor. Incidence of Urinary tract Infections (UTI) among patients attending Primary Health Centers in Anambra State, 2016.

[12] E.I. Omer, E. Fadil. Principles of Medical Microbiology. University students Library, Makkah AL Mukarramah edition, 1986.

[13] NCCLS, author. Performance Standards for Antimicrobial Susceptibility Testing, 11 th informational Supplement, NCCLS document M100-S11. Wayne, Pennyslyvia: National Committee for Clinical Laboratory Standards. (NCCLS); 2001.

[14] O.H, Bankole, O. Richard, O. Mitsan, A.A. Joshua. Urinary tract infection in a rural community in Nigeria. North American Journal of Medical Sciences. Vol. 3 no 2, 75-77, 2011.

[15] Z. Doudz, C. Affif. Escherichia coli Isolated from Urinary Tract Infections of Lebanese Patients between 2000 and 2009, Epidemiology and Profile of Resistance, 2011.

[16] MMDT; Bacterial Infections, (2005); Merk Manual.

[17] R. Omoregie, J.O. Erebor, I. Ahonkai, J.O. Isobor, H.O. Ogefero. Observed changes in the prevalence of Uropathogen in Benin City, Nigeria. NZJ Med Lab Sci., Vol 62, 29-31, 2008.

[18] R. Omoregie, N.O. Eghefona, Urinary tract infection among asymptomatic HIV patients in Benin City, Nigeria. Br. J Biomed Sc,Vol 66 No.4, 190-193, 2009.

[19] B.A. Akinola, C,Nwabuisi, A.P. Aboyeji, N.S. Ajayi, F. Adeola, O.F. Olurotimi. Asymptomatic Bacteriuria in Antenatal Patients in Ilorin, Nigeria. Oman Medical Journal, Vol 27, No 1, 31-35, 2012.

[20] S R. Rahman, M.F. Ahmed, A. Begum. Occurrence of Urinary Tract Infection in Adolescent and Adult Women of Shanty town in Dhaka City, Bangladesh. Vol. 24 No 2, 145-154, 2014.

[21] K.Mezue, C. Ofong, D.Nmezi, G G. Ugochukwu-Obi. Antibiotic Sensitivity Patterns in Urinary Tract Infections at a Tertiary Hospital. Journal of the University of Nigeria Medical Students, 2006.

[22] D.R Schmidt, A.E Sobota. An examination of the antiadherence activity of Cranberry juice on urinary and non-urinary bacterial isolates. 55:173-181, 1988

[23] T. Alraek, L.I.F. Soedal, S.U.Fagerheim, A. Digranes, A. Baerheim. Acupuncture treatment in the prevention of uncomplicated recurrent lower urinary tract infections in adult women. American Journal Public health. Vol. 92: 1609-11, 2002.

[24] G. Reid, A.W. Bruce. Probiotics to prevent Urinary tract infections: The rationale and evidence. World Journal Urology. Vol. 24: 28-32, 2006.

[25] E.V. Kul'Chavenia, A.A. Efficacy of Uro-vaxom in recurrent infectious inflammatory disease of the urogenital system.Urologia 4:7-11, 2011. 